\title{
Experimental Analysis of Human Touch Activated Self-healing Body Energy: Gyoki Body Resonancing \\ Vidan Damljanovic ${ }^{1}$ and Oliver Faehnle ${ }^{2^{*}}$ \\ ${ }^{1}$ Head of physiotherapy practice, Au, Switzerland \\ ${ }^{2}$ Applied optics phycisist, St. Gallen, Switzerland \\ "Corresponding author: Oliver Faehnle, Applied optics phycisist, St. Gallen, Switzerland, Tel: 41792634011; E-mail: olifaehnle@gmail.com \\ Received date: October 26, 2018; Accepted date: November 8, 2018; Published date: November 13, 2018
}

Copyright: (c) 2018 Damljanovic V, et al. This is an open-access article distributed under the terms of the Creative Commons Attribution License, which permits unrestricted use, distribution, and reproduction in any medium, provided the original author and source are credited.

\begin{abstract}
An experimental analysis has been carried out applying infrared monitoring demonstrating that empty minded gyoki skin contacting is capable of activating human's bio intelligence and KI generating energy at injured body parts activating self-healing processes. This effect rises without that the injured body part has been touched directly and can only be generated if the touching person is skilled in gassyo gyoki.
\end{abstract}

Keywords: Seiki; Shiatsu; Bio-intelligence; Resonance

\section{Introduction}

If we travel back in evolution and analyze the origin of medical mammal activities, we find close body contact and kind touching among the earliest healing attempts.

This approach exists until today, where we touch and embrace our babies in order to support their healing processes which are being carried out by bio intelligence. Hence, the etymology of the English word «contact» reflects this matter.

Analyzing its two word-forming elements «con» meaning together and «tact» meaning the sense of touch and feeling, we find a pointer to the ancient process of two beings that are communication with each other by touch, stimulating feelings by bio intelligence.

For ages, e.g. shiatsu has been applied to initiate body healing processes by human touch applying pressure to designated body areas [1-6].

With the rise of modern medicine, these bio intelligence processes have been more and more chemically initiated and taken over by modern medical measures. Nevertheless, our bodies are still capable of initiating healing processes by pure bio intelligence and skin contact is a powerful portal to initiate it [7].

In Europe, Hippocrates, the founder of modern medicine, already described about 2400 years ago that if a difference in temperature on the human skin is found, a pathological abnormality is probable [8]. He smeared a thin layer of wet mud on a patient's body for the purpose of investigating areas that dried first.

Seiki is an independent method of treatment that Akinobu Kishi Sensei for more than 30 years practiced and constantly evolved.

Seiki is a method that brings out the essence of Shiatsu-authentic touch in absolute presence and easy being-to view human nature and all things as they really are-and therefore it has for all manual therapist and shiatsu students a deeper meaning [9].
This paper presents experimental analyses of human touch activated self-healing body energy by monitoring the rise of local body temperature as a direct reaction to human touch.

\section{Experiments}

State-of-the-Art infrared photography [10] (infrared screening) has been applied monitoring changes of body temperature distributions in the near skin area of humans while proband's bio intelligence and $\mathrm{Ki}$ (living energy flow) has been activated through touching him/her by gyoki (applying gassyo-gyoki contacting the proband with a «breathing hand»).

Two sets of experiments have been conducted analyzing the rise of human touch activated self-healing body energy.

Firstly, typical body reactions of patients to a gyoki touch being applied by a skilled seiki therapist have been monitored showing the rise of local body temperature at injured body parts.

Subsequently, a healthy proband has been tested varying the way of touch comparing a skilled gyoki touch with a non-gyoki touch.

\section{Layout of experiments}

All probants have been tested in the same room and have been monitored applying the same infrared camera. All experiments have been carried out applying one frozen set of testing parameters, such as camera resolution, measuring range as well as the background room temperature.

All probants where sitting quietly for 10 minutes prior to being tested in order to ensure a calm atmosphere without any excitement and gyoki touch has been applied by a highly skilled seiki therapist.

The applied infrared camera10 has a resolution of $0.1^{\circ} \mathrm{C}$ and the spectral range has been kept constant throughout the tests monitoring changes in local body temperature caused by gyoki. Figure 1 shows a typical picture measuring the temperature distribution of $\mathrm{Mr}$. Damljanovic's hands. 


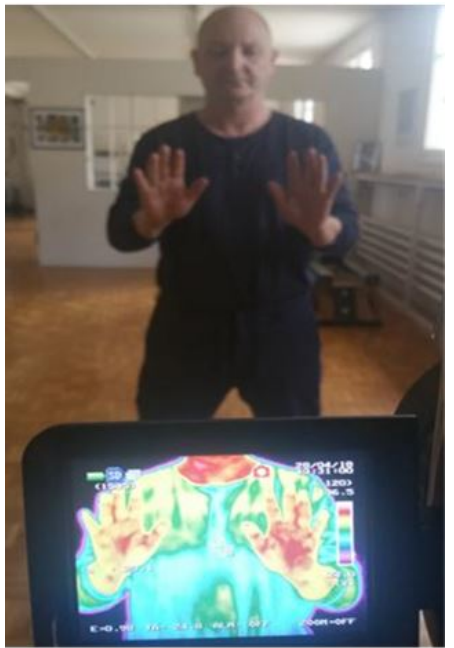

Figure 1: Measuring principle applying an infrared camera to monitor probands temperature distribution of the body part under test, in this case the hands of the seiki therapist Mr. Damljanovic.

\section{Monitoring patients with known health problems being touched by gyoki}

In a first set of experiments, Mr. Damljanovic, a seiki therapist applied gyoki touch to patients. Various patients with known health problems have been monitored by demonstrating a gyoki touch (applying a breathing hand) that is, not in contact with the injured part of the body, but stimulates the body to build up energy at the very part of the body where the problem is: This could be deterministically measured by in process infrared screening detecting.

A significant rise of local skin temperatures as an indication of bio intelligence initiating KI and self-healing processes (See Figure 2 and Figure 3 before wa-ki touch and Figure 4 and Figure 5 after wa-ki touch has been applied).

Typically, after a gyoki contact of about 2 minutes, a rise in local body temperature of about $1.5^{\circ} \mathrm{C}-2^{\circ} \mathrm{C}$ could be measured deterministically.

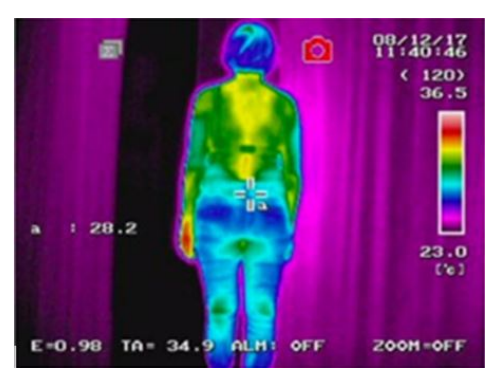

Figure 2: Proband-a (lung problems) before gassyo gyoki featuring $31.64^{\circ} \mathrm{C}$ in the upper back area.

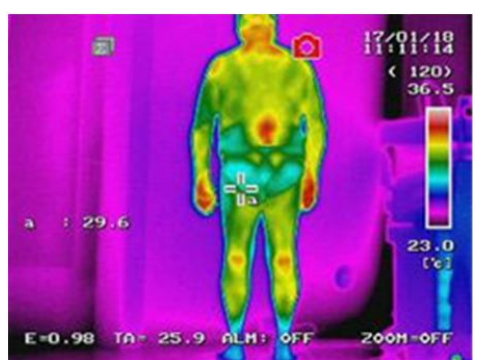

Figure 3: Proband-b (back pain problems) before gassyo gyoki featuring $31.30^{\circ} \mathrm{C}$ in the upper back area.

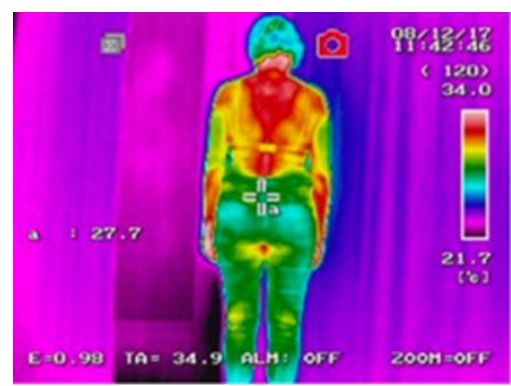

Figure 4: Proband-a after 2 minutes gassyo gyoki featuring $32.30^{\circ} \mathrm{C}$ in the upper back area: An increase of $0.66^{\circ} \mathrm{C}$ body temperature.

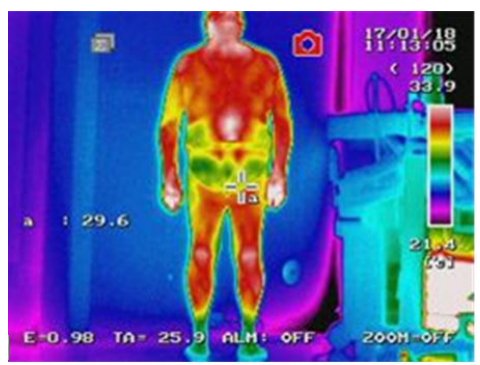

Figure 5: Proband-b after 2 minutes gassyo gyoki featuring $32.98^{\circ} \mathrm{C}$ in the upper back area: $\mathrm{An}$ increase of $1.7^{\circ} \mathrm{C}$ body temperature.

\section{Monitoring a healthy proband being touched by gyoki}

In the second set of experiment, the co-author who has currently not known health problems was screened by infrared video while being touched at his upper right arm by Mr Damljanovic's hand (each time for about 2 minutes and without applying pressure). Three successive tests have been carried out: Non gyoki contact applying hand contact without an empty mind state (Figure 6 shows Mr. Damljanovic's hand). This caused no rise in body temperature.

Non gyoki contact with previously heated hands by friction just before touching, Mr. Damljanovic rubbed his hands and consequently heat generated (Figure 7). Later hands were contacted immediately and without gyoki. Figure 8 shows probands are temperature distributions after having being touched for two minutes at the upper right arm. 
Citation: Damljanovic V, Faehnle O (2018) Experimental Analysis of Human Touch Activated Self-healing Body Energy: Gyoki Body Resonancing. Altern Integr Med 7: 270. doi:10.4172/2327-5162.1000270

Page 3 of 4

Finally Mr. Damljanovic applied calmly a high level gyoki contact (without rubbing his hands) to probands arm causing a substantial rise in body temperature in probands shoulders area (an increase of about $2^{\circ} \mathrm{C}$ ) shown in Figure 9 together with gyoki caused rise of temperature of Mr. Damljanovic's hands after having applied 2 minutes of gyoki (Figure 10). Please note that proband, the shoulder was damaged several years ago, still feeling uncomfortable in the upper shoulder area which got activated by gyoki touch.

Finally, after the final testing, Figure 11 shows again a low level of temperature of Mr Damljanovic's hands.

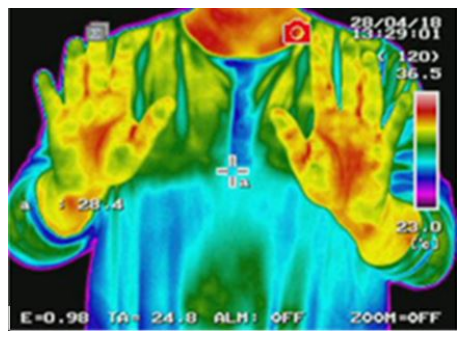

Figure 6: Mr Damljanovic's hands without rubbing, before the experiments $\left(32.6^{\circ} \mathrm{C}\right)$.

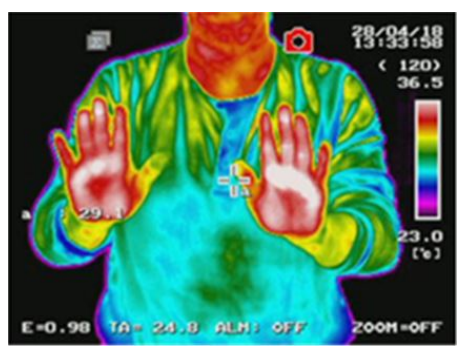

Figure 7: Mr Damljanovic's hands directly after rubbing and right before being applied to probands arm $\left(36^{\circ} \mathrm{C}\right)$.

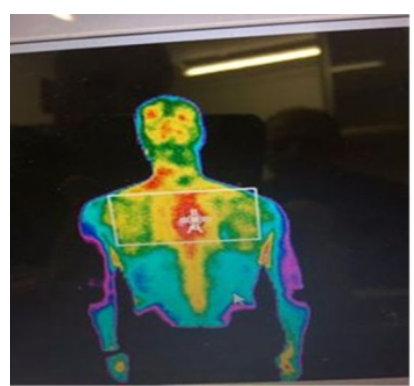

Figure 8: Probands temperature after 2 minutes of being contacted by friction heated hands (that are shown in Figure 7).

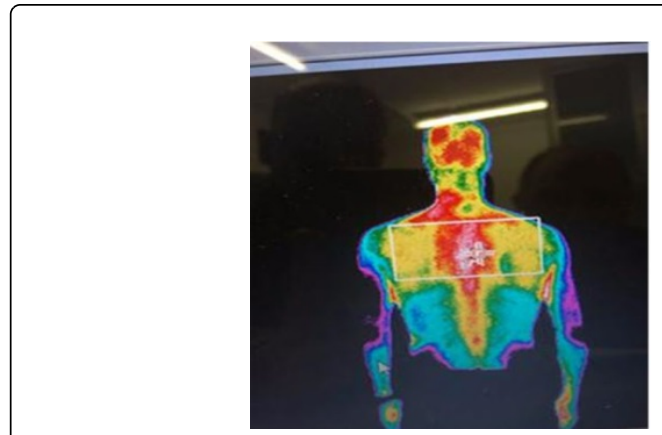

Figure 9: Probands temperature after being touched applying gyoki (without any pre-heated hands); Note that body temperature in the upper shoulder area is $2^{\circ} \mathrm{C}$ higher than the hands heated with friction (Figure 8).

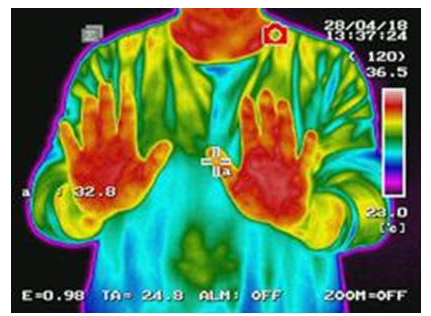

Figure 10: Mr Damljanovic's hands directly after applying gyoki.

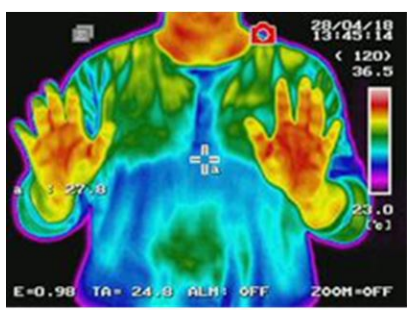

Figure 11: Mr Damljanovic's hands again reached their initial temperature after experiments were stopped (compare with Figure $6)$.

\section{Conclusion}

The effect of gyoki initiated rise of temperature at injured body parts has been analyzed experimentally. To that aim, infrared screening has been applied comparing levels of local body temperature before and directly after gyoki contact which was not applied at the injured body part but at another place at probands body.

Two sets of experiments have been conducted.

Firstly, typical body reactions of patients to a gyoki touch being applied by a highly skilled seiki therapist have been monitored showing the significant rise of local body temperature at injured body parts of about $0.5^{\circ} \mathrm{C}$ to $2^{\circ} \mathrm{C}$ that could be measured deterministically. 
Subsequently, a healthy proband has been tested varying the way of touch comparing a skilled gyoki touch with a non-gyoki touch. To that aim, three sets of experiments have been conducted. In a first set of tests proband had been touched without seiki skills being applied causing no significant rise in body temperature. In a second set of experiments proband was again touched without seiki skills (no gyoki touch being applied) but this time the seiki therapist heated up his hands surfaces by friction prior to touching (Figure 7); Again causing no significant rise in probands body temperature (Figure 8). Finally, seiki therapist applied a gyoki touch (Figure 6) causing a local rise in probands body temperature at his shoulders which had been injured several years ago still feeling uncomfortable (Figure 9).

These significant results demonstrate that empty minded gyoki skin contacting is capable of activating human's bio intelligence and KI generating energy at injured body parts activating self-healing processes. This effect rises without that the injured body part has been touched directly and can only be generated if the touching person is skilled in gassyo gyoki. The detected temperature rise is a strong indication that seiki causes a local increase in blood circulation enabling self-healing.

Currently, more investigations focusing on the transport mechanisms and on the time dependency between touch and the rise of heat are under investigation.

In conclusion, we presented evidence for the rise of local body temperature at injured body parts induced by human gyoki touch. Consequently, we are currently investigating the detection of selfhealing processes applying state-of-the-art measuring technologies following the trail along a better understanding of human regeneration.

\section{References}

1. Robinson N, Lorenc A, Liao X (2011) The evidence for Shiatsu: A systematic review of Shiatsu and acupressure. BMC Complementary and Alternative Medicine 11: 88.

2. Saito H (2000) Preventing and resolving post-laparotomy intestinal obstruction: An effective Shiatsu method. American J Chinese Med 28: 141-145.

3. Brady LH, Henry K, Luth JF, Casper-Bruett (2001) The effects of Shiatsu on lower back pain. J Holistic Nursing 19; 57-70.

4. Villani V, Prosperini L, Palombini F, Orzi F, Sette G (2017) Single-blind, randomized, pilot study combining shiatsu and amitriptyline in refractory primary headaches Neurol Sci 38: 999-1007.

5. Bouheret B (2016) Therapeutic shiatsu for patients and carers. Rev Infirm 218: 40-41.

6. Lanza G, Centonze SS, Destro G, Vella V, Bellomo M, et al. (2018) Shiatsu as an adjuvant therapy for depression in patients with Alzheimer's disease: A pilot study. Complement Ther Med 38: 74-78.

7. Teimoori B, Rajabi S, Navvabi-Rigi SD, Arbabisarjou A (2015) Evaluation effect of shiatsu technique on labor induction in post-term pregnancy. Glob J Health Sci 7: 177-183.

8. Ring EF (2004) The historical development of thermal imaging in medicine. Rheumatology (Oxford) 43: 800-802.

9. Akinobu Kishi and Alice Whieldon (2011) Sei-Ki: Life in resonance, the secret art of shiatsu. Jessica Kingsley Publishers, London.

10. InfReC infrared R300SR Series, Nippon Avionics Co. 